\title{
Book Review: Open: The Philosophy and Practices that are Revolutionizing Education and Science
}

Editors: Rajiv S. Jhangiani and Robert Biswas-Diener (London: Ubiquity Press, 2017, 304 pages. https://www.ubiquitypress.com/site/books/10.5334/bbc/)

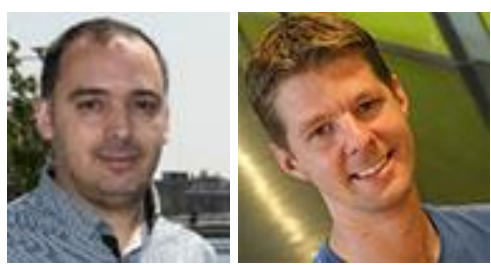

Reviewed by: Nelson R. Jorge, IHE Delft Institute for Water Education, and Martijn Ouwehand, Delft University of Technology

When exploring the idea of Open, presenting different perspectives and covering various interconnected domains is a meaningful effort to provide a comprehensive overview of this multidimensional concept. Open education, open pedagogy, open science, open access, open textbooks, open educational resources, open-source, and open practices are all concepts related to the common idea of removing barriers, providing access, and stimulating progress.

The book Open: The Philosophy and Practices that are Revolutionizing Education and Science, edited by Rajiv Jhangiani and Robert Biswas-Diener, presents a combination of interesting viewpoints and developments related to various dimensions of the open movement: open education, open science, open access, and open pedagogy.

The introductory part of the book explores the concept of open education with a focus on open educational resources (OER). The chapters here included provide an explanation of the history of OER, its development and distribution, with David Wiley's $5 \mathrm{R}$ activities in mind - retain, reuse, revise, remix, redistribute - and the role of Creative Commons licensing, allowing easy access and editing with common tools, generally available.

In fact, Creative Commons played a critical role in the evolution of OER, contributing to its proliferation and leading to the possibility of reducing costs in higher education, for example with the adoption of open textbooks as opposed to expensive Big Publisher Books (BPBs), a curious term used in this book by Regan Gurung. Nevertheless, benefits for OER shouldn't be limited to cost savings. Other benefits include the contextualization and enhancement of OER, and the freedom learners have to access trial subjects, complement, and enrich their formal study.

The quality of OER is also an interesting topic brought up to the discussion. While some may consider price as a way to reveal quality (the more expensive the better), this judgement doesn't make sense when talking about OER. Just like with any other educational resource, faculty have the responsibility to 
analyse and review it before it's added to the teaching and learning process. Knowing the author of a certain OER and that it has been reviewed by peers makes it easier, with the advantage of knowing which parts could be improved and having the freedom to actually improve it. Therefore, the quality of OER can be understood as something dynamic since its content can continuously be revised and optimized.

The second part of the book is about Open Practices, including chapters about Open Science and Open Pedagogy.

The transition towards Open Science is an ongoing effort that is dependent on a profound cultural change - in researchers' behaviour, in the infrastructure that supports their research, and in the commercial business models that dominate the sector. The Center for Open Science (COS) is a meaningful initiative to encourage open science practices and accelerate a change process. The COS aims to improve the quality of research by increasing its openness, integrity, and reproducibility. Strategies to achieve their mission include the evaluation of empirical evidence, appropriate training of academic researchers, and incentives that promote the sharing of research output.

As reviewers working in the open education field, we see the addition of an Open Pedagogy chapter as a very relevant and important one, since it goes beyond reusing OER. Open Pedagogy entails an educational transformation where more interactive and meaningful contact time replaces traditional lectures. OER is critical in this pedagogical change but as something to critique and further develop, something to revise and add-on to, instead of an end product that is simply found and adopted. A truly student-centred approach can then be fostered, offering students the possibility to curate and create.

The third part of the book contains several case studies that describe practical examples of open initiatives, reinforcing the first two parts of the book.

David Wiley's chapter has, however, a different approach. In "Iterating toward openness: Lessons learned on a personal journey," Wiley shares insights and reflections on his work in open education. After almost 20 years of contributions to the field, Wiley concludes that it's time to move beyond narrow conceptions of OER to a more comprehensive Open Education Infrastructure, with four interdependent components: Open Competencies, Open Educational Resources, Open Assessments, and Open Credentials.

The book ends with a conclusion by the editors, where challenges and the future of the open movement are discussed.

In sum, this book provides insight into most of the currently relevant authors and developments in the open domain, offering a comprehensive overview. Although the idea of this book initiated with a focus on open psychology, it managed to gather a broader collection of different chapters that can be read separately. Due to this variety, we see it as a good starting point for people new to the concept of Open, while some chapters are definitely interesting for people who are already in the field.

Independent of the readers' background, we come to conclude that there's still a lot to be done and that a socio-cultural change is necessary to realize Open as a default practice in the coming future. We believe that reading this book can definitely contribute to the necessary change. 
Book Review: Open: The Philosophy and Practices that are Revolutionizing Education and Science Jorge and Ouwehand

\section{Athabasca}

University

(c) (1) 